\title{
Efeito do tempo de exposição a uma atmosfera coqueificante na microestrutura e nas propriedades de um concreto refratário usado na indústria petroquímica
}

\author{
(Effect of the exposure time in cokemaking atmosphere on the \\ microstructure and properties of a refractory castable used in the \\ petrochemical industry)
}

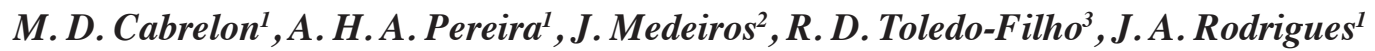 \\ ${ }^{1}$ Grupo de Engenharia de Microestrutura de Materiais - GEMM, Departamento de Engenharia de Materiais - \\ DEMa, Universidade Federal de S. Carlos - UFSCar, Rod. Washington Luiz, km 235, S. Carlos, SP, 13565-905 \\ ${ }^{2}$ CENPES, Petróleo Brasileiro S/A - PETROBRAS \\ ${ }^{3}$ Laboratório de Estruturas e Materiais - LABEST, COPPE, UFRJ, Rio de Janeiro, RJ \\ marcelodezena@gmail.com
}

\begin{abstract}
Resumo
Os concretos refratários usados em unidades de craqueamento catalítico fluidizado (UFCC) podem sofrer deterioração pela deposição de coque durante o processo de produção de hidrocarbonetos leves, ocasionando a diminuição do tempo de funcionamento do reator e conseqüiente perda financeira para as petroquímicas. Diversos estudos foram feitos, porém nenhum deles aponta conclusivamente para a parcela que esta deposição tem na deterioração do concreto, permanecendo a dúvida se ele é o responsável pelos danos observados macroscopicamente no riser de uma UFCC. Este trabalho visou estudar o efeito do tempo de exposição a uma atmosfera coqueificante sobre um concreto refratário anti-erosivo, classe C, buscando identificar mudanças nas propriedades físicas e microestruturais que evidenciem o mecanismo de degradação e que possam fornecer subsídios para análises conclusivas acerca do entendimento do fenômeno. Para isso, prepararam-se amostras de um concreto usado industrialmente em UFCC, submetidas a um processo de coqueificação forçado em reator piloto. Fixou-se a temperatura e a taxa de aquecimento em $540{ }^{\circ} \mathrm{C}$ e $50{ }^{\circ} \mathrm{C} / \mathrm{h}$, respectivamente, variando-se os tempos de exposição ao gás propeno em 10 , $60,120,240$ e $480 \mathrm{~h}$. Os corpos de prova tiveram suas microestruturas caracterizadas via microscopia ótica e eletrônica de varredura e suas fases por difração de raios X. Outros ensaios complementares foram necessários para o entendimento do fenômeno. Os resultados mostraram que a superfície e a microestrutura do material gradativamente se impregnam de coque, que preenche os poros, as microtrincas e as trincas. Não foram encontradas evidências de microtrincamento em torno dos poros da matriz do concreto preenchidos com coque, porém os agregados apresentam algum tipo de deterioração com o tempo de exposição ao propeno, não necessariamente causados diretamente pelo coque.
\end{abstract}

Palavras-chave: concreto refratário, petróleo, UFCC, propeno, coque, microestrutura.

Abstract

Refractory castables used in Fluidized Catalytic Cracking Units (FCCU) are said to deteriorate due coke formation during the production of light hydrocarbons, causing a shortening in the operating time of the reactor. Consequently, a significant financial loss for the petrochemical will occur. Several studies have been carried out, but none of them showed clearly how much is the contribution of the coke for the concrete final deterioration. It still remains the doubt if the coke is the responsible for the damage observed macroscopically in a FCCU's riser. In this way, this work aimed to study the effect of the time in a cokemaking atmosphere on an anti-erosive class-C refractory castable, seeking for microstructural changes or on physical properties that indicate degradation mechanisms and give support to the understanding of the phenomenon. Samples of an industrial refractory castable used in petrochemical units were prepared and subjected to a forced cokemaking process in a simulation reactor. The temperature and the heating rate were kept constant at $540{ }^{\circ} \mathrm{C}$ and $50{ }^{\circ} \mathrm{C} / \mathrm{h}$, respectively. The values of 10 , 60,120 , 240 and $480 \mathrm{~h}$ were used for the time of exposition to the propene gas. The microstructure of the samples was characterized through optical and scanning electron microscopy and its mineralogical phases through X-ray diffraction. Complementary analyses were necessary to a better understanding of the phenomenon. The results show that the surface and the microstructure are gradually impregnated by coke, which fills up pores, microcracks and cracks. Evidences of microcracking around the coke filled pores were not found. However, many aggregates present some type of deterioration related to the time of exposition to propene. Those damages are not necessarily caused by coke directly.

Keywords: refractory castable, petroleum, FCCU, propene, coke, microstructure. 


\section{INTRODUÇÃO}

A indústria petroquímica atravessa um momento de expressivo crescimento e representa uma parcela consideravelmente elevada para a sustentação da economia brasileira em momentos de crise, como a de 2009-2010. Com a descoberta do petróleo do pré-sal, os investimentos em $P \& D$ tendem a crescer ainda mais e as perspectivas da PETROBRAS, apresentadas em seu plano de negócios 2010-2014, é da disponibilização de mais de US\$ 5 bilhões para este período [1]. Com isso, a exigência de desenvolvimento e melhoria de todos os materiais envolvidos no processo petroquímico se torna um requisito primordial para consolidar o setor, fazendo com que exista o desenvolvimento de tecnologia internamente ao invés da importação da mesma.

Dentre os materiais cerâmicos a serem aprimorados, os concretos refratários merecem destaque, pois sua utilização se estende a diversas etapas do refino. Porém a literatura voltada aos refratários para o setor petroquímico é escassa, o que dificulta a solução dos problemas indústrias muito complexos. Torna-se necessário, então, a realização de estudos básicos que visem à compreensão dos fenômenos envolvidos nos diversos processos petroquímicos, com destaque àqueles do refino. Dentre alguns problemas observados freqüentemente na indústria do petróleo, a deposição de coque nos refratários que revestem o riser de uma Unidade de Craqueamento Catalítico Fluidizado (UFCC) é encarada como um dos mais graves, causando dificuldades operacionais e a perda de rendimento técnico e financeiro. Levando-se em consideração que a parada de uma UFCC causa uma elevada perda financeira, a melhoria do material e/ou a compreensão do fenômeno proporcionará

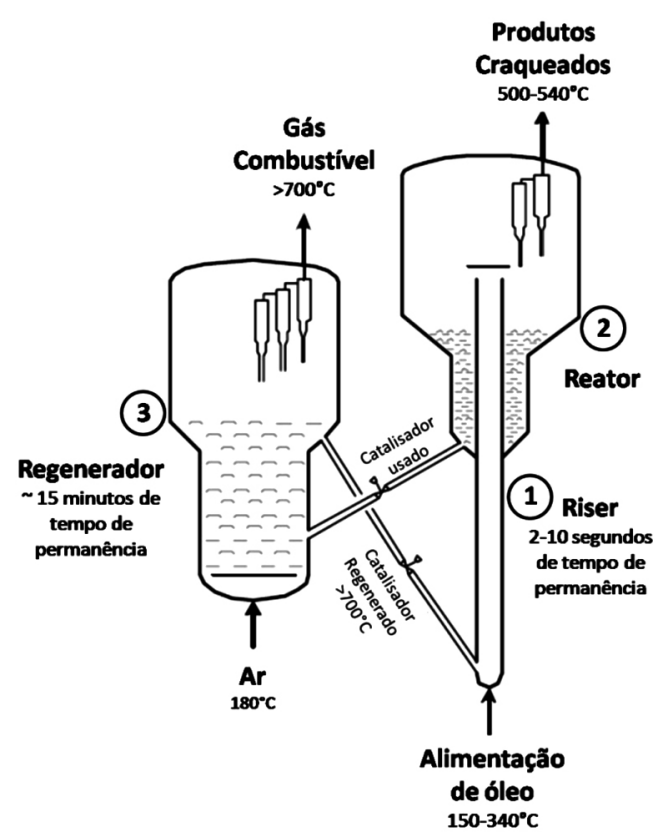

Figura 1: Representação esquemática de uma moderna UFCC [4]. [Figure 1: Schematic representation of a modern FCCU [4].] uma economia importante. As unidades de craqueamento catalítico fluidizado são compostas principalmente por três partes posicionadas seqüencialmente, como ilustra a Fig. 1 [2-4]: 1) Riser - tubulação vertical com dimensões típicas de 0,6 a $1,8 \mathrm{~m}$ de diâmetro e altura variando entre 22 e $50 \mathrm{~m}$, revestido por um concreto refratário com alta resistência a erosão, atuando em uma faixa de temperatura entre 650 e $800{ }^{\circ} \mathrm{C}$ na qual a mistura óleo/catalisador/vapor d'água é injetada e convertida em hidrocarbonetos leves; 2 ) Reator - antigamente, com o uso de catalisadores de baixa atividade, as reações de craqueamento eram finalizadas no reator, porém com o emprego de catalisadores zeolíticos ele passou a ter a função de vaso-separador, direcionando para a coluna de fracionamento as moléculas craqueadas para resfriamento e classificação e para o regenerador o catalisador desativado; 3) Regenerador - por meio do contato com ar quente, o catalisador, impregnado com coque e conseqüentemente sem atividade catalítica, é reativado pela remoção dos hidrocarbonetos pesados e do coque dos centros ácidos necessários para a catálise heterogênea.

A impregnação pelo coque em concretos refratários usados principalmente na região do riser vem sendo apontada como uma das fontes de danos que mais prejudicam o processo, causando freqüentes paradas de produção e consequientemente uma importante perda financeira e de rendimento do processo. O coque pode ser formado por meio de dois mecanismos: 1) craqueamento térmico e 2) craqueamento catalítico. O craqueamento térmico é um processo não-catalítico que ocorre por meio da formação de radicais livres [3] que se recombinam gerando uma quantidade excessiva de coque e produtos na forma de gases (com menos de 3 carbonos), em detrimento dos produtos líquidos, como a gasolina. Em contrapartida, o craqueamento catalítico tem como característica o uso de um catalisador com propriedades ácidas que promove a formação de compostos de maior cadeia carbônica (com mais de 3 carbonos) e o coque, sempre tendo como intermediário reativo um carbocátion [5]. Evidências de degradação dos refratários pela formação do coque por craqueamento catalítico são conhecidas e estudadas pela indústria siderúrgica desde o século XIX, porém para a petroquímica a literatura é vaga. Algumas hipóteses foram baseadas no que se observa na siderurgia, bem como os ataques sofridos diretamente pelos catalisadores zeolíticos em um ambiente de UFCC. São elas:

1) Deposição de carbono pela ação do CO: problema afetado e agravado por materiais que apresentem pequenas quantidades de ferro na forma metálica ou do óxido em sua constituição. $O$ ferro atua promovendo a catálise heterogênea, que na presença de $\mathrm{CO}$, sofre recombinações, até desencadear a formação do coque. Abaixo se encontra a seqüência de reações que resume o caminho de formação do coque. Nelas o ferro, que pode ser proveniente de reduções dos respectivos óxidos ou já presente na forma metálica, reage com o monóxido de carbono, formando um carbeto de ferro, que se recombinará até a regeneração total do ferro metálico e a formação de coque em todas as etapas de reações. 


$$
\begin{aligned}
& \mathrm{Fe}+\mathrm{CO}_{\text {adsorvido }} \rightarrow \mathrm{FeC}+1 / 2 \mathrm{O}_{2} \\
& 2 \mathrm{FeC} \rightarrow \mathrm{Fe}_{2} \mathrm{C}+\text { grafite } \\
& 3 \mathrm{Fe}_{2} \mathrm{C} \rightarrow 2 \mathrm{Fe}_{3} \mathrm{C}+\text { grafite } \\
& \mathrm{Fe}_{3} \mathrm{C} \rightarrow 3 \mathrm{Fe}+\text { grafite }
\end{aligned}
$$

Neste sentido, estipulam-se limites aceitáveis de compostos de ferro nos materiais refratários, de $\mathrm{Fe} \leq 0,1 \%$ e $\mathrm{Fe}_{\mathrm{x}} \mathrm{O}_{\mathrm{y}} \leq 0,2 \%$ [6]. A forma de deterioração dos refratários por esse mecanismo seria evidenciada macroscopicamente pela ação expansiva provocada pela deposição do carbono na matriz e/ou uma ação retrativa causada pela redução do $\mathrm{Fe}_{2} \mathrm{O}_{3}$ pelo $\mathrm{CO}$.

2) Deposição de carbono por meio da reação com hidrocarbonetos: esta hipótese tem ganhado força devido a alguns artigos que a apresentam como forma complexa de deterioração, não só de refratários, mas principalmente dos catalisadores a base de zeólitas usados no craqueamento catalítico. O mesmo mecanismo de ataque no processo de desativação de zeólitas cerâmicas no ambiente agressivo de uma UFCC foi citado [7]. Esta hipótese baseia-se na decomposição de compostos aromáticos para formação do coque por diversos caminhos de reação. Na Fig. 2, está representada a seqüência de reações plausíveis para a formação do coque levando-se em consideração a decomposição de compostos aromáticos [3].

Diversos são os mecanismos que governam estas reações e elas são intensificadas devido a algumas características dos refratários, dentre as quais é possível citar a presença de sítios ácidos nos compostos que constituem o material, que podem ser sítios de Bronsted ou Lewis. Estes sítios ácidos atuam na etapa de adsorção dos hidrocarbonetos precursores do coque e são tanto mais irreversíveis quanto mais fortes forem o caráter ácido do sítio. Este conceito, transposto dos catalisadores, pode ser útil no caso dos refratários, pelo fato dos concretos refratários usados no riser serem

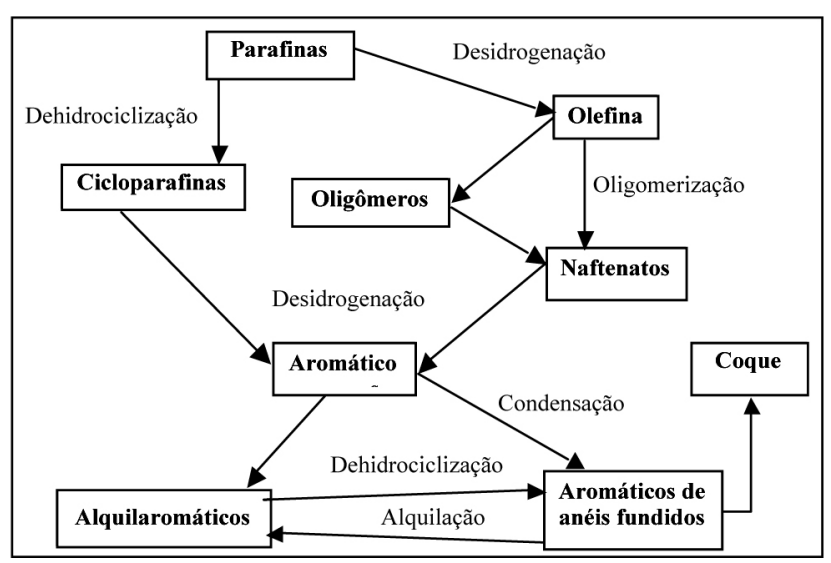

Figura 2: Esquema representando as diversas reações de formação do coque a partir de compostos aromáticos [3].

[Figure 2: Schematic representation of the various coke formation reactions from aromatic compounds [3].] de aluminossilicatos. Se a alumina usada for a $\alpha-\mathrm{Al}_{2} \mathrm{O}_{3}$ calcinada, a tendência de o material ser inerte é grande, porém se nele existir pequenas quantidades de $\gamma$ ou $\theta-\mathrm{Al}_{2} \mathrm{O}_{3}$, a atividade dos sítios ácidos será catalisada [8], gerando um ponto de adsorção dos compostos orgânicos precursores do coque que posteriormente gerará uma região de deterioração química. A correlação entre o local de aplicação destes refratários e o tipo de mecanismo predominante, sugere que exista uma predominância variável dos dois mecanismos. No fundo do riser, onde se tem uma atmosfera altamente rica em CO, observa-se a carbonetação dos metais, sugerindo a predominância da formação do coque via reação de decomposição do CO. Nas regiões subseqüentes do riser, espera-se não se encontrar uma pressão parcial elevada de CO. Porém, a corrosão acontece com relevância, o que leva à consideração do mecanismo de decomposição via compostos aromáticos.

A incorporação do coque na microestrutura dos concretos refratários causa, em termos de propriedades físico-mecânicas, certa controvérsia. O preenchimento dos poros com coque melhora consideravelmente as propriedades mecânicas do concreto, pela formação de um corpo misto composto por agregados, matriz e estrutura de poros preenchida com coque [2] . Esta associação causa a melhoria das propriedades conforme ilustra a Tabela I.

Tabela I - Propriedades de um concreto refratário de alta resistência a erosão sem uso em comparação com o similar coqueificado [9].

[Table I - Properties of a not used high erosion-resistant refractory castable in comparison with a similar one exposed to cokemaking atmosphere [9].]

\begin{tabular}{lcc}
\hline \multicolumn{1}{c}{ Propriedade } & \multicolumn{2}{c}{ Estado do material } \\
& Novo & Coqueificado \\
\hline $\begin{array}{l}\text { Densidade aparente } \\
\left(\mathrm{g} . \mathrm{cm}^{-3}\right)\end{array}$ & 2,70 & 2,89 \\
Porosidade aparente $(\%)$ & 27,0 & 7,6 \\
Resistência à compressão $(\mathrm{MPa})$ & 101 & 170 \\
Perda máxima por erosão $\left(\mathrm{cm}^{3}\right)$ & $5,5-6,5$ & 2,9 \\
\hline
\end{tabular}

Acoqueificação e a conseqüente impregnação da estrutura de poros do concreto refratário causam uma diminuição de $72 \%$ na porosidade aparente e um aumento de $7 \%$ na densidade aparente. Essas alterações nas propriedades físicas refletemse diretamente no comportamento mecânico, causando um aumento de $70 \%$ na resistência a compressão e diminuição de aproximadamente $50 \%$ na perda por erosão. Além desses efeitos, foi mostrado que o material coqueificado apresenta maior coeficiente de expansão térmica e maior condutividade térmica, em relação ao material não-coqueificado [9]. Neste contexto, o presente trabalho tem por objetivo verificar a influência do tempo de exposição à atmosfera coqueificante de propeno nas propriedades de um concreto refratário 
usado comumente na região do riser petroquímico, a fim de se buscar indícios de comportamentos que expliquem os problemas de deterioração observados macroscopicamente e atribuídos ao coque.

\section{MATERIAIS E MÉTODOS}

O estudo foi iniciado por meio da seleção de um concreto refratário comercial de ultra-baixo cimento $(1,0 \%>\mathrm{CaO}>$ $0,2 \%$ [10]) que se enquadrasse na linha dos materiais antierosivos classe C, codificado como REF. Assim que recebido, o material granulado foi homogeneizado em um misturador duplo-cone e separado em frações de $2,5 \mathrm{~kg}$ para cada batelada de massa a ser batida. Em um reômetro com torque fixo misturou-se o material seco por $1 \mathrm{~min}$, com posterior adição de 8,5\% de água sob agitação constante por mais $5 \mathrm{~min}$. Foram moldados corpos de prova cúbicos de $2,5 \mathrm{~cm}$ de aresta e prismáticos com $15,0 \mathrm{~cm} \times 2,5 \mathrm{~cm} \times 2,5 \mathrm{~cm}$, sobre uma mesa vibratória. Depois, os corpos de prova foram curados por 48 $\mathrm{h}$ em câmara úmida e secos por mais $24 \mathrm{~h}$ em estufa a $110^{\circ} \mathrm{C}$. Uma parte destes corpos de prova foi submetida ao processo de coqueificação forçada, usando-se um reator piloto do CENPES-PETROBRAS, RJ, que consistiu na sua exposição a uma atmosfera de propeno, por períodos de tempo de 10 , $60,120,240$ e $480 \mathrm{~h}$, a $540{ }^{\circ} \mathrm{C}$, com taxa de aquecimento $50{ }^{\circ} \mathrm{C} / \mathrm{h}$ e pressão interna da câmara $2 \mathrm{~atm}$. Transcorridos os ciclos térmicos, as amostras passaram para as etapas de caracterização das propriedades físicas, mineralógicas, térmicas, microestruturais e mecânicas. Também foi preparada uma amostra em forno tipo mufla, mantendo-se as condições operantes no reator piloto $\left(540{ }^{\circ} \mathrm{C} / 60 \mathrm{~h}\right.$ e taxa de aquecimento $50{ }^{\circ} \mathrm{C} / \mathrm{h}$ ), porém sem a presença do gás coqueificante de

Tabela II - Códigos e históricos das amostras analisadas. [Table II - Codes and description of the samples.]

\begin{tabular}{ll}
\hline Código & Histórico \\
REF & \\
\hline
\end{tabular}

Pó Mistura seca do material granulado

\section{Curado Concreto refratário somente curado}

Cal. $60 \mathrm{~h}$ Concreto refratário calcinado a $540{ }^{\circ} \mathrm{C} / 60$ $\mathrm{h}$ em atmosfera de ar

10h Concreto refratário coqueificado a 540

${ }^{\circ} \mathrm{C} / 10 \mathrm{~h}$ em atmosfera de propeno

$60 \mathrm{~h} \quad$ Concreto refratário coqueificado a 540

${ }^{\circ} \mathrm{C} / 60 \mathrm{~h}$ em atmosfera de propeno

Concreto refratário coqueificado a 540

$120 \mathrm{~h} \quad{ }^{\circ} \mathrm{C} / 120 \mathrm{~h} \mathrm{em}$ atmosfera de propeno

$240 \mathrm{~h}$

Concreto refratário coqueificado a 540

${ }^{\circ} \mathrm{C} / 240 \mathrm{~h}$ em atmosfera de propeno

$480 \mathrm{~h}$

Concreto refratário coqueificado a 540

${ }^{\circ} \mathrm{C} / 480 \mathrm{~h}$ em atmosfera de propeno propeno. Esta amostra, codificada como REF Cal. 60h, foi utilizada como um padrão para comparações descritas adiante.

Na Tabela II encontram-se os códigos atribuídos a cada corpo de prova e os correspondentes históricos.

Propriedades físicas: foram determinadas a absorção de água (AA), porosidade (PA) e densidade (DA) aparentes via método de Arquimedes, com imersão dos corpos de prova cúbicos em querosene, nos diversos estágios do trabalho, buscando-se traçar um perfil destas propriedades em função do tempo de exposição à atmosfera coqueificante.

Propriedades mecânicas: foi avaliado o módulo de Young e o amortecimento dos corpos de prova prismáticos, com dimensões $15,0 \mathrm{~cm} \times 2,5 \mathrm{~cm} \times 2,5 \mathrm{~cm}$, das amostras curadas e calcinadas e coqueificadas.

O módulo de Young foi caracterizado pela técnica de excitação por impulso de acordo com a norma ASTM E1876 [11] simultaneamente com o amortecimento, empregandose o método do decremento logarítmico para este último [12]. Para essas caracterizações foi utilizado o equipamento Sonelastic (ATCP Engenharia Física, S. Carlos, SP). Na técnica de excitação por impulso, ou das frequêencias naturais de vibração, o corpo de prova é apoiado sobre fios e recebe um leve impulso e gera uma resposta acústica [13]. Esta resposta acústica, após devidamente processada pelo software do equipamento, revela as frequiências naturais de vibração do corpo de prova dependendo das condições de contorno mecânicas. Conhecendo estas frequiências, as dimensões e a massa do corpo de prova é possível se calcular os módulos elásticos a partir das equações de Picket [14].

Perda de massa: foram realizados testes de perda de

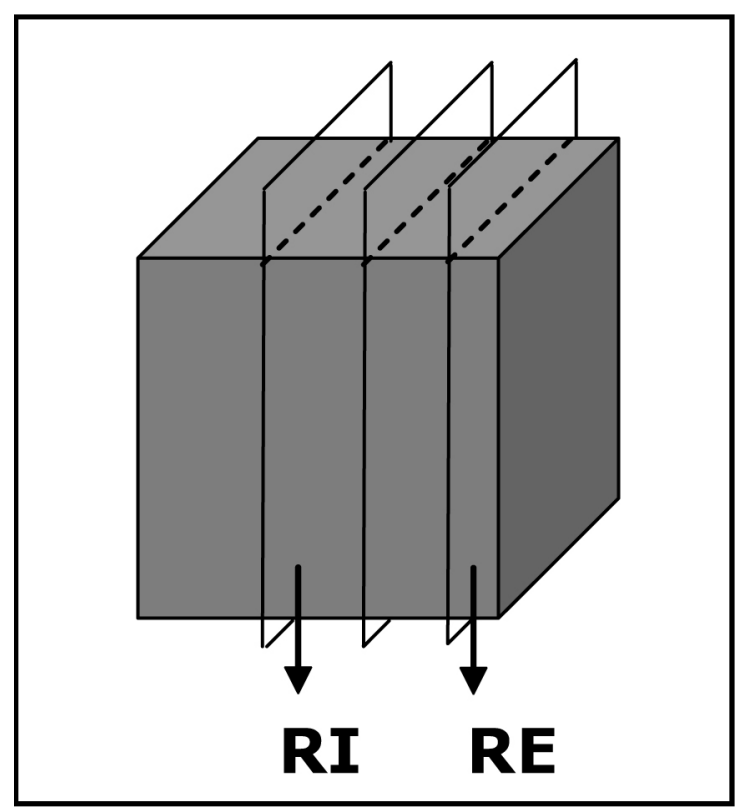

Figura 3: Esquema da retirada das frações dos corpos de prova cúbicos para análise de perda de massa e de DRX: Região externa (RE) e Região interna (RI).

[Figure 3: Scheme of the samples fractions for the weight loss and XRD analysis: External Region (RE) and Internal Region (RI).] 
massa por calcinação, usando-se frações moídas das regiões internas (RI) dos corpos de prova cúbicos (vide Fig. 3). Para isso, as mesmas foram calcinadas em forno tipo mufla a $1000{ }^{\circ} \mathrm{C} / 1 \mathrm{~h}$ com taxa de aquecimento $1{ }^{\circ} \mathrm{C} \cdot \mathrm{min}^{-1}$.

Caracterização de fases: as fases mineralógicas foram obtidas mediante difração de raios $\mathrm{X}$ (DRX) em equipamento Bruker D8 Focus, com radiação de Cu, filtro de $\mathrm{Ni}$, operando com $40 \mathrm{kV}$ e $40 \mathrm{~mA}$. A rotina utilizada teve $2 \theta$ variando entre 5 e $80^{\circ}$ e velocidade de $2^{\circ}$. $\mathrm{min}^{-1}$. Analisaramse alíquotas do material particulado como recebido, do concreto curado não-coqueificado e da região externa (RE, Fig. 3) dos corpos de prova cúbicos coqueificados em diversos tempos de patamar. Também se analisou uma fração do coque superficial formado sobre as amostras de 240 h de coqueificação. Vale ressaltar que todas as análises foram feitas em pós moídos abaixo de $44 \mu \mathrm{m}$.

Caracterização microestrutural: as amostras cúbicas foram inicialmente seccionadas ao meio com um disco diamantado, a seco, tendo sido uma metade embutida em resina polimérica de pega química, deixando-se em evidência a secção interna do cubo. Procedeu-se ao polimento com uma sequiência de lixas de 80 a 1500 mesh com posterior polimento em politriz automática com pasta de diamante, com tamanho de partícula variando entre 9 e $1 \mu \mathrm{m}$ sobre pano umedecido com etilenoglicol. As amostras polidas foram analisadas inicialmente por microscopia óptica digital, em microscópio Zeiss Axio Scope, e posteriormente por microscopia eletrônica de varredura, em equipamentos TMP Philips.

\section{RESULTADOS E DISCUSSÃO}

A Tabela III traz os valores das propriedades físicas das amostras que serão utilizadas como padrões para comparação e na Fig. 4 estão expostos os resultados das mesmas propriedades físicas dos concretos coqueificados em função do tempo.

Analisando-se os resultados pertencentes ao grupo das propriedades físicas, nota-se a correlação entre a porosidade aparente e a absorção de água dos corpos de prova, o que possibilita a sua análise conjunta. Há o aumento de PA e AA quando o material curado sofre uma queima em atmosfera de ar $\left(\right.$ a $\left.540{ }^{\circ} \mathrm{C} / 60 \mathrm{~h}\right)$, resultado de um processo de desidratação e destruição de ligações hidráulicas, causando a elevação das porosidades aberta e fechada à medida que as hidroxilas

Tabela III - Resultados de porosidade aparente (PA), absorção de água (AA) e densidade aparente (DA) dos concretos refratários REF Curado e REF Cal. 60h (vide Tabela II). [Table III - Apparent porosity (PA), water absorption (AA) and apparent density (DA) of the samples: REF Curado and REF Cal.60h.]

\begin{tabular}{cccc}
\hline Amostras & PA $(\%)$ & AA $(\%)$ & DA $\left(\mathrm{g} / \mathrm{cm}^{3}\right)$ \\
\hline REF Curado & $12,76 \pm 0,24$ & $4,37 \pm 0,12$ & $2,92 \pm 0,03$ \\
REF Cal. 60h & $17,67 \pm 0,19$ & $6,28 \pm 0,08$ & $2,81 \pm 0,01$ \\
\hline
\end{tabular}

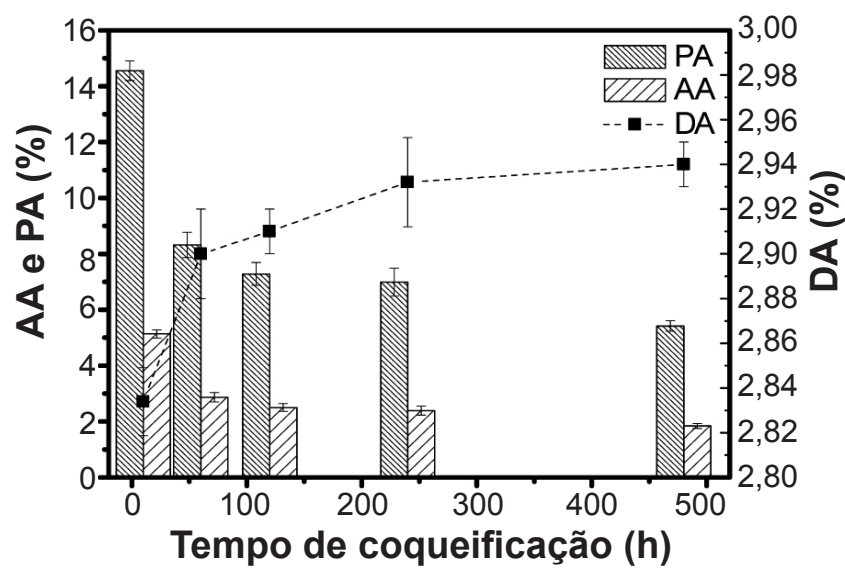

Figura 4: Porosidade aparente (PA), absorção de água (AA) e densidade aparente (DA) do concreto refratário após diferentes tempos de coqueificação (10, 60, 120, 240 e 480 h).

[Figure 4: Apparent porosity (PA), water absorption (AA) and apparent density $(D A)$ of the coking samples after different soaking time $(10,60,120,240$ and $480 \mathrm{~h})$.]

deixam vazios na estrutura, além da diminuição da densidade aparente (ver Tabela III). O tempo de exposição à atmosfera de propeno causa a formação do coque que preenche os poros abertos (e também aqueles internos e conectados com a superfície) dos corpos de prova. Isto pode ser observado pelo aumento da densidade aparente e as conseqüentes diminuições de AA e PA (ver Fig. 4). O concreto calcinado ao ar apresentava valores de PA e AA de $17,7 \%$ e $6,8 \%$, respectivamente (Tabela III). Com o inicio da impregnação pelo coque após $10 \mathrm{~h}$ em atmosfera de propeno, verifica-se que a porosidade do material diminui, passando de $17,7 \%$ para $14,6 \%$, decorrente do preenchimento dos poros pelo coque formado. Ao se atingir $60 \mathrm{~h}$ de coqueificação, ocorre um decréscimo significativo de PA, atingindo a faixa dos $8 \%$. A partir deste ponto não se observa alterações tão drásticas com o aumento do tempo de exposição, o que sugere que a $60 \mathrm{~h}$ já se atingiu patamares de saturação da estrutura porosa, não agregando uma quantidade maior de coque no seu interior. A impregnação pelo coque gera o aumento de DA, de 2,81 até $2,94 \mathrm{~g}_{\mathrm{cm}} \mathrm{cm}^{-3}$, readquirindo praticamente o valor apresentado pelo material somente curado $\left(2,92 \mathrm{~g} . \mathrm{cm}^{-3}\right)$. Todos estes resultados físicos podem se refletir diretamente no comportamento mecânico do material. Para isso o modulo de Young (E) e o amortecimento $(\delta)$ foram medidos e os resultados estão expostos na Fig. 5. Vale informar que os corpos de prova coqueificados por $10 \mathrm{~h}$ não tiveram suas propriedades mecânicas avaliadas.

O modulo de Young dos materiais (Fig. 5a) diminuiu à medida que se destroem as ligações hidráulicas dos corpos de prova (REF curado x REF Cal. 60h, linhas tracejadas horizontais) causando o enfraquecimento da estrutura. A partir do início da coqueificação verifica-se o aumento do modulo elástico devido, principalmente, ao preenchimento dos poros pelo coque. Se analisarmos e evolução de E em função do tempo, pode-se perceber que a exposição à atmosfera de propeno causa a sua elevação até valores consideravelmente maiores que o material somente curado, 

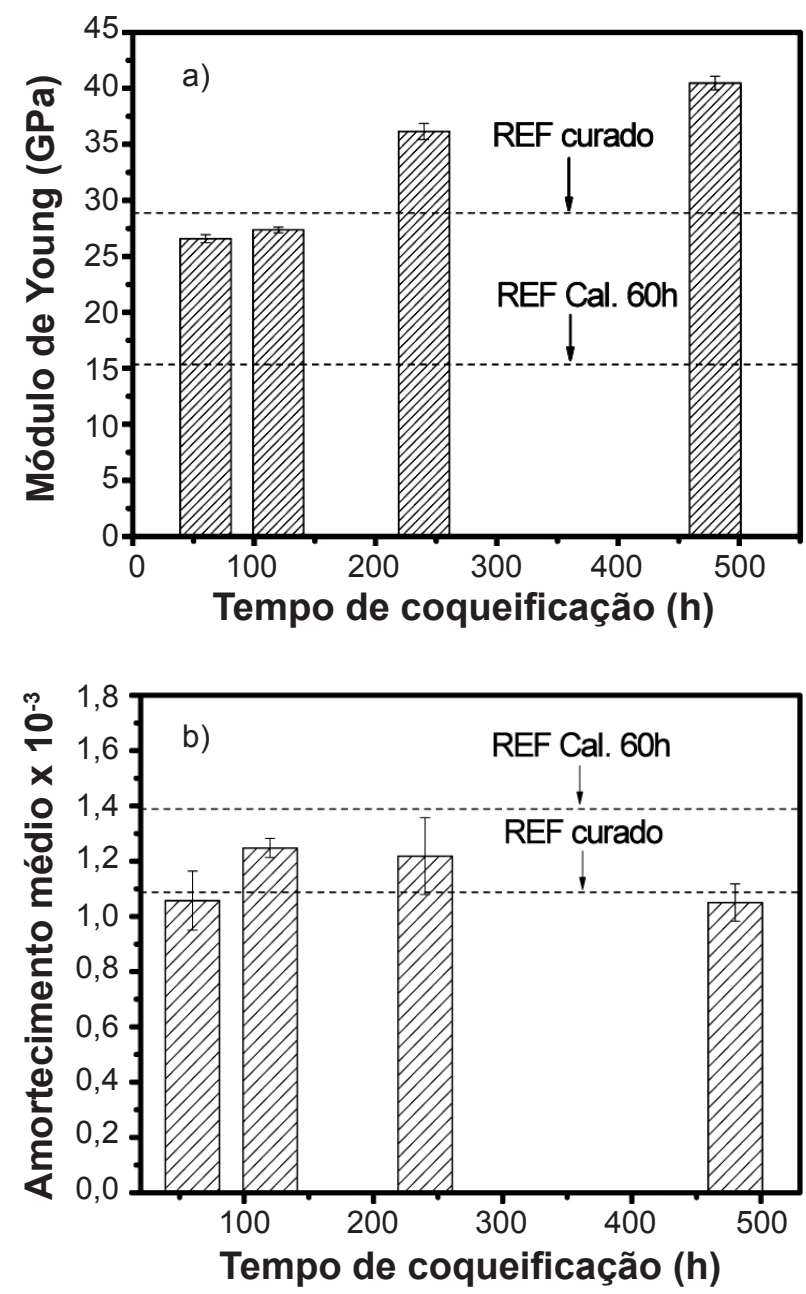

Figura 5: Resultados de a) Módulo de Young (E) e b) Amortecimento (ठ), para as diversas condições usadas nesta investigação.

[Figure 5: Results of a) Young's modulus (E) and b) Damping $(\delta)$, for the different conditions used in this work.]

tendendo à estabilização da propriedade, devido à saturação da estrutura porosa com o coque. Os resultados sobre o amortecimento (Fig. 5b) apresentaram comportamento interessante. Analisando-se apenas o efeito da calcinação do material em atmosfera não coqueificante (REF curado x REF Cal. 60h, linhas tracejadas horizontais), verifica-se que a calcinação do material, deu origem a um concreto com porosidade mais alta, elevando consideravelmente o amortecimento de vibrações mecânicas, pelo surgimento de mais superfícies de atrito. Quando se inicia a impregnação com o coque, o amortecimento diminui em comparação com as referências, já que ocorre o fechamento de poros pelo coque. Com o transcorrer do tempo de coqueificação, essa característica apresenta um máximo em $120 \mathrm{~h}$ com posterior decaimento até $480 \mathrm{~h}$, voltando a valores de amortecimento comparáveis com o corpo de prova coqueificado por $60 \mathrm{~h}$. Ainda não é clara a razão desse comportamento que envolve o desaparecimento da porosidade e as características intrínsecas de atrito interno do próprio coque. Porém, devese destacar que as variações mostradas na Fig. 5.b. são pouco significativas se levarmos em consideração outros efeitos que causam modificação no amortecimento. Esse é o caso de danos por choque térmico que chegam a alterar em ordens de grandeza o valor do amortecimento.

As fases mineralógicas foram investigadas de maneira qualitativa, com o intuído de se identificar a formação de alguma estrutura cristalina diferente em algum estágio estudado, que pudesse dar subsídios para interpretar o aparecimento de danos. Na Fig. 6 está exposto o padrão de difração da camada de coque formada na superfície da amostra REF 240h.

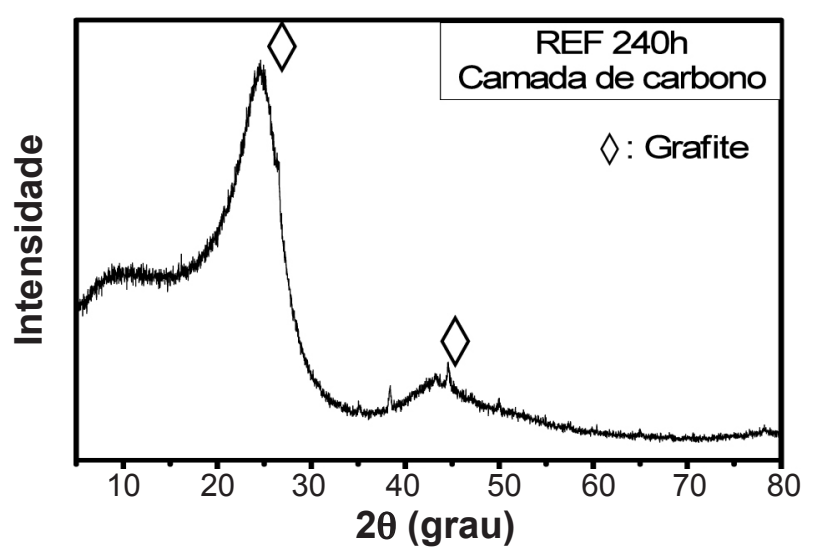

Figura 6: Difratograma de raios $\mathrm{X}$ da camada de coque formada na superfície da amostra coqueificada a $540{ }^{\circ} \mathrm{C} / 240 \mathrm{~h}$.

[Figure 6: XRD pattern of the coke layer formed on the sample REF 240 h surface.]

Verifica-se a existência de uma banda bem intensa em $25^{\circ}$ e outras duas mais discretas em $10^{\circ}$ e $45^{\circ}$. Estas bandas largas são decorrentes da presença de material amorfo e de cristais muito defeituosos [15]. Comparando-se com os picos de difração do carbono grafite, vê-se uma tendência do material em se organizar nesta estrutura, na qual a banda mais intensa estaria associada ao plano (002) que difrata em $26,5^{\circ}$, enquanto a banda mais discreta seria relativa ao plano (101), que difrata em $44,5^{\circ}$. Comparando-se com resultados [16], verifica-se que este comportamento do carbono amorfo, cristalizando-se na fase grafite, em condições de temperatura e pressão amenas, é conhecido, pois esta é a fase termodinamicamente mais fácil de ser obtida. Encontramse expostos na Fig. 7 os padrões de difração evidenciando as fases presentes na camada mais externa dos corpos de prova cúbicos para os diferentes tempos de coqueificação, comparados com o material de partida REF Pó (matériaprima) e com o material curado.

As análises dos padrões de difração que evidenciam as fases cristalinas (Fig. 7) nos fornecem poucas informações de como o tempo de permanência em atmosfera coqueificante influencia as fases mineralógicas do material. As mesmas fases presentes no material precursor são também observadas tanto no material curado quanto naqueles submetidos à coqueificação forçada. Está presente como fase majoritária o quartzo $\left(\mathrm{SiO}_{2}\right)$, e as demais fases em proporções menores: Mulita $\left(\mathrm{Al}_{6} \mathrm{Si}_{2} \mathrm{O}_{13}\right)$, Cianita $\left(\mathrm{Al}_{2} \mathrm{SiO}_{5}\right)$, $\beta$-Cristobalita $\left(\mathrm{SiO}_{2}\right)$ e Coríndon $\left(\mathrm{Al}_{2} \mathrm{O}_{3}\right)$. O grafite foi 


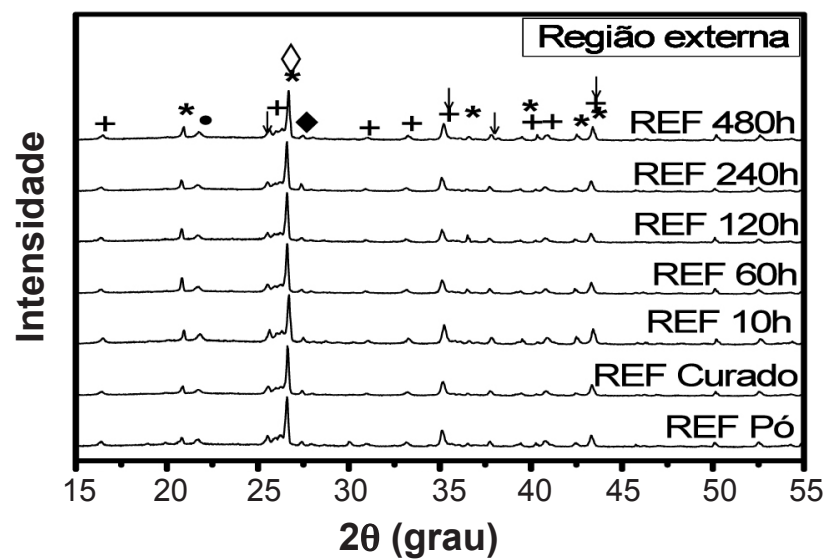

Figura 7: Difratogramas de raios $\mathrm{X}$ da região mais externa (RE na Fig. 3) das amostras coqueificadas por 10, 60, 120, 240 e $480 \mathrm{~h} \mathrm{em}$ comparação com a matéria-prima (REF Pó) e a amostra curada e secada a $110{ }^{\circ} \mathrm{C}$ (+:Mulita; *: Quartzo; $\diamond$ : Grafite; $\bullet$ : Cristobalita; ४: Cianita; $\downarrow$ : Corindon).

[Figure 7: XRD pattern of the external region for the samples exposed to cokemaking atmosphere for 10, 60,120,240 and 480 h in comparison with the reference samples: REF Pó and REF Curado $110{ }^{\circ} \mathrm{C}$. (+: Mullite; *: Quartz; $\diamond$ : Graphite; $\bullet$ : Cristobalite; $\bullet:$ Kyanite; $\downarrow$ : Corundum.]

inserido na análise somente para mostrar que ele apresenta picos coincidentes com o quartzo o que dificultaria a sua identificação. De qualquer forma, no padrão de difração do coque (Fig. 6), por apresentar baixa intensidade, decorrente do seu caráter amorfo e/ou de alta desordem estrutural, sua identificação seria complicada. Como a faixa de atuação de um riser petroquímico está na faixa de 500 a $800^{\circ} \mathrm{C}$, pode-se considerar que todos os materiais ali presentes serão inertes e não sofrerão nenhuma mudança significativa com exceção dos hidratos e da sílica. Isso explica o fato de observarmos as mesmas fases cristalinas no material granulado (REF Pó) e nos materiais coqueificados a $540{ }^{\circ} \mathrm{C}$. Esta pouca variação no comportamento mineralógico das amostras indica que os danos que possam vir a ser observados serão consequiência direta de efeitos decorrentes do coque e de transformações de fase apenas no caso da sílica.

Com intuito de se identificar a quantidade de carbono impregnado em função do tempo de exposição à atmosfera de propeno, foram retiradas fatias internas dos corpos de prova cúbicos (RI na Fig. 3), descartando-se as faces laterais, desprezando-se assim o efeito do crescimento da camada externa de coque. A Fig. 8 expõe estes resultados, segundo a seguinte equação.

$$
\mathrm{PF}_{\text {total }}=\mathrm{PF}_{\text {desidratação }}+\mathrm{PF}_{\text {coque }}
$$

na qual $\mathrm{PF}_{\text {total }}$ é a perda de massa total da amostra, $\mathrm{PF}_{\text {desidratação }}$ é a perda de massa devido a processos de desidratação e $\mathrm{PF}_{\text {coque }}$ é a perda de massa relativa a decomposição do coque.

Nota-se que o material granulado original (REF Pó) apresenta perda por calcinação próxima de zero, o que era esperado devido à presença somente de fases anidras e/ou que não sofrem nenhum tipo de decomposição

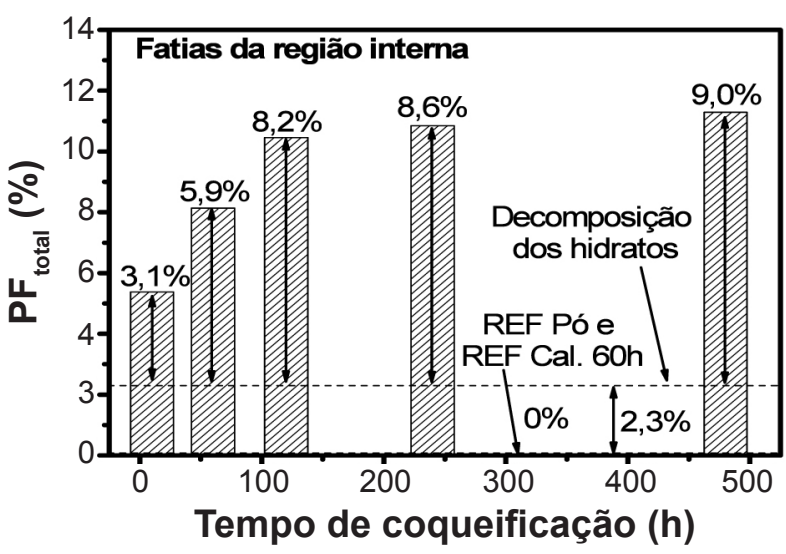

Figura 8: Perda de massa (PF) da região interna dos corpos de prova cúbicos para as diversas amostras analisadas, segundo a equação $\mathrm{E}$. [Figure 8: Weight loss (PF) of the cubic specimen's inner of the analyzed samples, according to the equation E.]

térmica. Após o processo de moldagem e cura o concreto se hidrata resultando numa perda por calcinação de 2,3\% (linha tracejada na Fig. 8). Durante o tratamento térmico sem atmosfera coqueificante de propeno, os hidratos são decompostos e a perda por calcinação posterior volta a ser zero. O processo de coqueificação provoca um acréscimo significativo na perda ao fogo do concreto refratário em todos os tempos de patamar analisados. Considerandose somente a perda ao fogo relativa ao coque $\left(\mathrm{PF}_{\text {coque }}\right)$, verifica-se que para $10 \mathrm{~h}$ de exposição tem-se um aumento de $3,1 \%$, relativo a oxidação do coque que estava presente dentro dos poros dos corpos de prova. Esta tendência de aumento ainda é significativa para a amostra exposta por 60 $\mathrm{h}$, tendo PF igual a 5,9\%. As amostras de 120,240 e $480 \mathrm{~h}$ mostraram a tendência de saturação dos poros com coque, com os valores de 8,2, 8,6 e 9,0\%, respectivamente. Isto é indício de que este seria o ponto de saturação da estrutura porosa do material refratário analisado e que a partir disso, o processo de coqueificação seguiria dois caminhos: 1) continuar impregnando os poros e trincas a ponto de causar tensões, que por sua vez causariam novas trincas capazes de danificar o refratário ou 2) cessar a impregnação interna, mas continuar o crescimento de uma camada externa de coque. Vale ressaltar que ambos os processos podem ocorrer concomitantemente e, de fato, para os tempos maiores de coqueificação observa-se a formação de espessa camada de coque (da ordem de milímetros) sobre as superfícies livres dos corpos de prova.

Para melhor entender a relação direta entre a impregnação de coque e a porosidade aparente, tratou-se os dados a fim de se obter a taxa de impregnação a partir da perda ao fogo do material coqueificado, de acordo com a seguinte equação:

$$
\mathrm{Tx}_{\text {impregną̧ão }}=\Delta \mathrm{m}_{\text {coque }} / \Delta \mathrm{T}
$$

na qual $T_{\text {impregnacão }}$ é a taxa de impregnação com o coque $\left(\mathrm{mg} \cdot \mathrm{h}^{-1}\right), \Delta \mathrm{m}_{\text {coque }}$ é a variação de massa relativa a decomposição/impregnação pelo coque em miligramas, e $\Delta t$ é o intervalo de tempo de exposição ao propeno em horas. A 
Fig. 9 apresenta a variação da taxa de impregnação (Equação F) em comparação com a porosidade aparente ao longo do tempo de exposição à atmosfera de propeno.

Conforme se aumenta o tempo de exposição à atmosfera

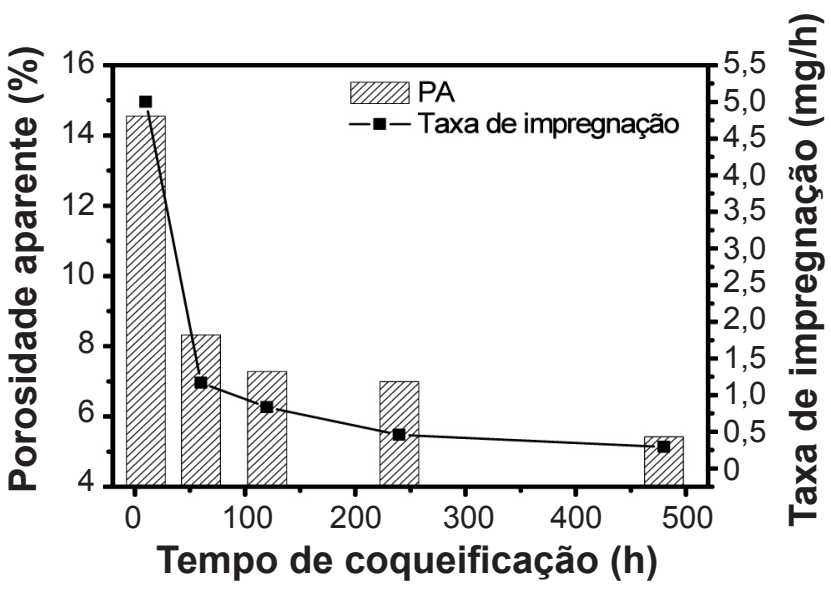

Figura 9: Taxa de impregnação média (Tx) e porosidade aparente (PA) em função do tempo de coqueificação.

[Figure 9: Average impregnation rate (Tx) and apparent porosity (PA) versus the cokemaking time.]

coqueificante diminui-se bruscamente a taxa de impregnação do coque na microestrutura interna do concreto. Este resultado tem boa correlação com a diminuição da porosidade aparente. Quando ela é alta, o coque se deposita na microestrutura interna com uma taxa elevada, chegando a níveis de $5,0 \mathrm{mg} \cdot \mathrm{h}^{-1}$. À medida que se fecham os poros, essa taxa cai até chegar a um ponto de tendência a estabilização ( $480 \mathrm{~h}$ de exposição ao propeno) com uma taxa de impregnação de somente $0,3 \mathrm{mg} \cdot \mathrm{h}^{-1}$, ou seja, apenas $6 \%$ do valor em $10 \mathrm{~h}$. A partir deste ponto a quantidade de coque

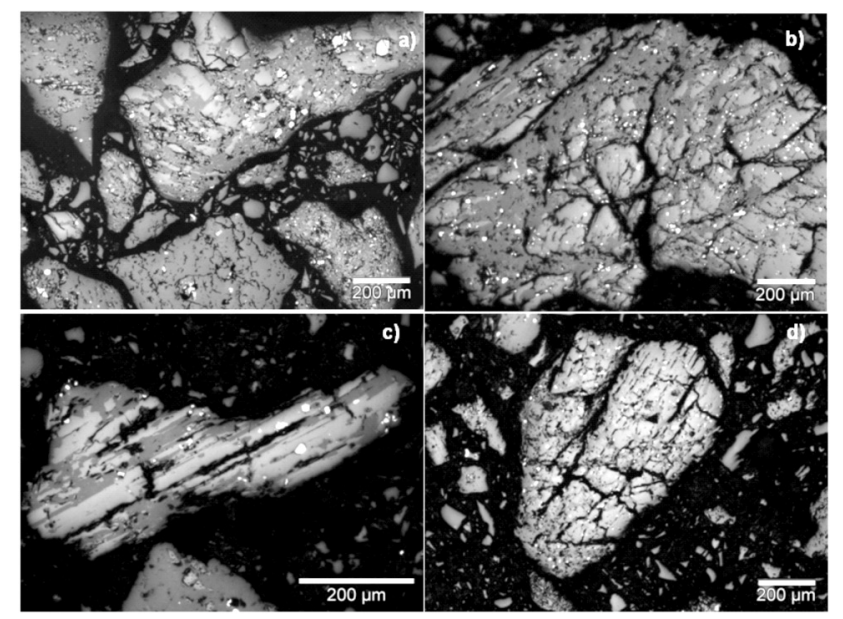

Figura 10: Micrografias óticas digitais evidenciando agregados similares em quatro estágios: a) REF Curado; b) REF 60h; c) REF 120h; REF; REF 240h.

[Figure 10: Digital Optical Micrographs showing similar aggregates in four stages: a) REF Curado; b) REF 60h; c) REF 120h; REF; REF 240h.]
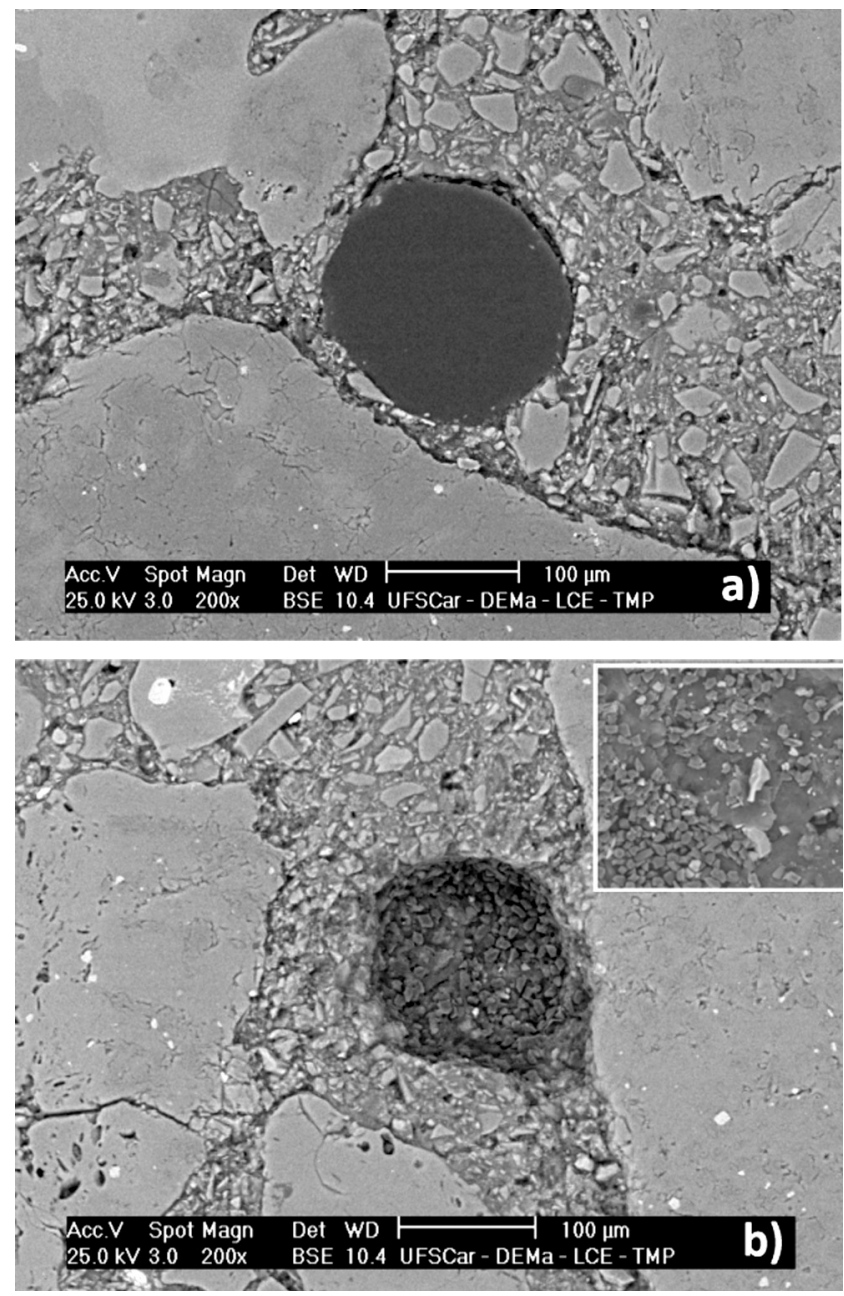

Figura 11: Micrografias de MEV de duas regiões da amostra coqueificada por $120 \mathrm{~h}$ : a) Região 1: poro preenchido com carbono (cinza escuro), b) Região 2: poro com vestígios de carbono - o detalhe amplia o interior do poro.

[Figure 11: SEM micrographs of coking samples for $120 \mathrm{~h}$ in two regions: a) Region 1: pore filled with carbon; b) Region 2: pore with carbon traces - the detail shows the pore's inner.]

depositado na microestrutura interna do concreto tende a ser mais próxima de zero, favorecendo o crescimento de uma crosta de coque na superfície dos corpos de prova, que foi observado principalmente nas amostras a partir de $240 \mathrm{~h}$ de exposição.

A partir daqui, os resultados expostos refletirão a região interna dos corpos de prova, bem como a forma de impregnação do carbono nos poros e os mecanismos que poderiam estar associados à geração de tensões e, por sua vez, provocar o aparecimento de danos. A Fig. 10 apresenta detalhadas micrografias óticas de um tipo de agregado muito encontrado neste de concreto, em diversos estágios de coqueificação comparado com o material somente curado.

Vê-se claramente que este tipo de agregado é formado por duas fases e que isso pode comprometer a resistência mecânica do mesmo, se ocorrer diferença de coeficientes de expansão térmica. Em termos de deterioração, pode- 
se fazer uma análise comparativa tomando a amostra curada (Fig. 10.a.) como referência. Nota-se que ocorre, aparentemente, um alargamento das trincas existentes em todas as amostras que sofreram o processo de coqueificação, independentemente do tempo de exposição à atmosfera de propeno. Este fato sugere duas hipóteses: 1) O coque atua causando a deterioração dos agregados, causando o alargamento das trincas neles existentes; 2) A alta permeabilidade do gás propeno, gerador do coque, permite que ele seja formado facilmente em trincas e poros do concreto de tal modo a preencher rapidamente qualquer tipo de defeito que possa ter surgido por eventos termomecânicos, não tendo o defeito em si ligação direta com o coque.

Analisar somente os agregados não permite $o$ entendimento do fenômeno como um todo, fazendo-se necessário a análise da matriz do concreto refratário. $\mathrm{Na}$ Fig. 11 estão expostas duas imagens da matriz da amostra coqueificada por $120 \mathrm{~h}$, obtidas com MEV em modo que evidencia a diferença de peso atômico dos componentes (BSE).

A Fig. 11a deixa claro um poro preenchido por algo mais leve que a matriz e que teria baixo peso atômico, como o carbono, que forma uma estrutura densa com característica betuminosa. Na Fig. 11.b., tem-se outra região da amostra analisada, onde se percebe claramente que algo foi arrancado de dentro de um poro semelhante àquele da Fig. 11a, pela ação do polimento da amostra. No poro remanescente, não se observa a presença de microtrincas radiais, que deixaria evidente que o coque teria gerado tensões suficientes para causar dano microscópico no material. O detalhe no canto superior direito da Fig. 11b mostra somente a presença de resquícios de coque no interior do poro. Também não se observa trincas associadas ao poro preenchido pelo coque da Fig. 11a, a não ser algo como um destacamento (parte superior do poro).

Fica clara a importância das caracterizações aqui apresentadas, pois elas permitirão o fechamento de trabalhos em andamento que avaliarão se o coque em si é ou não o responsável pela degradação do revestimento refratário observado em UFCC. O que fica claro até este ponto, é que o material coqueificado tem valores elevados de módulo elástico devido ao fechamento dos poros pelo coque, assim como foi verificado [3]. Porém, enquanto a matriz do concreto tem os seus poros fechados pelo coque sem evidência de microtrincamento ao seu redor, os agregados aparecem também impregnados de coque encontrando caminho pelas suas trincas e poros. Ainda não é possível afirmar que essas são trincas abertas por alguma pressão do coque ou se simplesmente as mesmas são consequiência de efeitos termomecânicos.

\section{CONCLUSÕES}

O tempo de exposição à atmosfera de propeno foi suficiente para causar a penetração do carbono e a formação do coque em todo o corpo de prova, fazendo com que as características físicas (PA, AA e DA), atingissem valores que tendem a saturação; em termos mecânicos, o preenchimento dos poros com coque causa um aumento considerável do módulo de Young do concreto, quando comparado com a amostra calcinada por $60 \mathrm{~h}$. Já o amortecimento de vibrações apresentou comportamento pouco sensível à exposição ao propeno, com variações consideradas pequenas e pouco representativas; a difração de raios $\mathrm{X}$ mostrou que não ocorre a formação de nenhuma fase cristalina nova em nenhuma condição analisada, devido às baixas temperaturas a que foram submetidos esses materiais. Isso nos sugere que qualquer dano micro ou macroscópico não será gerado pelo aparecimento de novas fases nos concretos, a não ser pela penetração do carbono ou por transformações da sílica; verificou-se o aumento da perda ao fogo dos materiais a medida que se aumenta o tempo de exposição à atmosfera de propeno, chegando até próximo da saturação; microestruturalmente, verificou-se a revelação de trincas dos agregados pelo coque com o aumento do tempo de coqueificação. Porém ainda não é claro se essas trincas são causadas diretamente por uma ação de pressão do coque ou por algum efeito termomecânico. Por outro lado, na matriz observou-se o preenchimento dos poros, porém sem nenhum tipo de microtrincamento radial gerado em torno dos poros.

\section{AGRADECIMENTOS}

Aos pesquisadores do CENPES, PETROBRAS, à Agência Nacional de Petróleo, ao Laboratório de Estruturas e Materiais, COPPE, UFRJ, ao Laboratório de Caracterizações Estruturais (LCE-UFSCar) e ao CNPq (Procs. 303061/2009-0, 301073/2006-6, 500621/2008-0, 503769/2010-0 e 141868/2008-2) pelos apoios concedidos nas diferentes etapas deste trabalho.

\section{REFERÊNCIAS}

[1]http://www2.petrobras.com.br/ri/portwebcastpresentation/ webcast_pn-2010-2014.pdf.

[2] E. Motoki, Y. Yoshimiz, U. Taikabutsu, Overseas 19, 3 (1999) 69-74.

[3] F. A. S. Serra, "Deterioração de concreto refratário em unidades de craqueamento catalítico pela adição do coque", Diss. Mestrado, PPGCEM-UFSCar, S. Carlos, SP (2002) 165 p.

[4] W. Vermeiren, J. P. Gilson, Top. Catal. 52 (2009) 11311161 .

[5] J. Biswas, I. E. Maxwell, Appl. Catalysis 63 (1990) 197 258.

[6] Y. T. Chien, Y. C. Ko, Am. Ceram. Soc. Bul. 62, 7 (1983) 779-786.

[7] H. S. Cerqueira, G. Caeiro, L. Costa, F. Ramôa-Ribeiro, J. Molecular Catalysis A: Chem. 292 (2008) 1-13.

[8] A. P . Borosy, J. Phys. Chem. 98 (1994) 13189-13194.

[9] M. S. Crowley, C. A. A. Schacht, Proc. Unified Int. Tech. Conf. Refractories, UNITECR' 97, New Orleans, EUA (1997) 1643-1652.

[10] W. E. Lee, W. Vieira, S. Zhang, K. Ghanbari-Ahari, H. 
Sarpooloky, C. Parr, Int. Mater. Rev. 46, 3 (2001) 145-167. [11] ASTM E 1876 - 07, "Standard Test Method for Dynamic Young's Modulus, Shear Modulus, and Poisson's Ratio by Impulse Excitation of Vibration", ASTM Standard, (June 2007).

[12] C. W. Silva, "Vibration Damping, Control, and Design", $1^{a}$ Ed., Taylor \& Francis (2007) 513.

[13] A. H. A. Pereira, M. Venet, T. Tonnesen, J. A. Rodrigues, Cerâmica 56 (2010) 118-122.
[14] G. Pickett, Am. Soc. Test. Mater. 45 (1945) 846-865. [15] H. Fan, Y. Li, S. Sang, Mater. Sci. Eng. A 528 (2011) 3177-3185.

[16] L. I. Medeiros, "Obtenção de nanocompósitos, nanodiamante sobre fibra de carbono e nanotubo de carbono sobre fibra de carbono", Diss. Mestrado Eng. e Tecnol. Espaciais, Ciência e Tecnologia de Materiais e Sensores, INPE, SP (2009).

(Rec.07/07/2011, Ac. 09/08/2011) 